\title{
LEI DE LICITAÇÕES E CONTRATOS ADMINISTRATIVOS (LEI 14.133/2021): O DIÁLOGO COMPETITIVO COMO NOVA MODALIDADE DE LICITAÇÃO
}

\section{José Antônio Remédio ${ }^{1}$}

RESUMO: A contratação de obras, serviços, compras e alienações pelo Poder Público, por expressa previsão constitucional, deve em regra ser precedida de licitação. A Lei 14.133/2021 rompe com os modelos clássicos de licitação anteriormente existentes e cria o diálogo competitivo como nova modalidade licitatória. A pesquisa objetiva analisar a modalidade licitatória denominada diálogo competitivo, em especial suas características, procedimento e importância. O método da pesquisa é o hipotético-dedutivo, com base na legislação, doutrina e jurisprudência. Conclui que o diálogo competitivo constitui importante instrumento para a transparência, celeridade, efetividade e segurança jurídica do processo licitatório atualmente disciplinado pela Lei 14.133/2021.

Palavras-chave: Contratos Administrativos; Diálogo Competitivo; Lei de Licitações e Contratos Administrativos; Licitações; Modalidades de Licitação; Procedimento do Diálogo Competitivo.

\section{BIDDING LAW AND ADMINISTRATIVE CONTRACTS (LAW 14.133/2021): THE COMPETIVE DIALOGUE AS A NEW BIDDING MODALITY}

\begin{abstract}
The contracting of works, services, purchases and disposals by the Public Power, by express constitutional provision, must as a rule be preceded by bidding. Law $14.133 / 2021$ breaks with the classic bidding models previously existing and creates competitive dialogue as a new bidding modality. The research aims to analyze the bidding modality called competitive dialogue, especially its characteristics, procedure and importance. The research method is hypothetical-deductive, based on legislation, doctrine and jurisprudence. It concludes that the competitive dialogue is an important instrument for the transparency, speed, effectiveness and legal security of the bidding process currently regulated by Law 14.133/2021.
\end{abstract}

Keywords: Administrative Contracts; Competitive Dialogue; Bidding Law and Administrative Contracts; Bids; Bidding Modalities; Competitive Dialogue Procedure.

\section{INTRODUÇÃO}

A licitação pública brasileira, cujo regime jurídico foi pautado nos últimos anos basicamente pelas Leis 8.666/1993, 10.520/2002 e 12.462/2011, é um dos institutos mais emblemáticos e polêmicos do Direito Administrativo.

\footnotetext{
${ }^{1}$ Pós-Doutor em Direito pela UENP. Doutor em Direito pela PUCSP. Mestre em Direito pela UNIMEP. Professor de Direito do Centro Universitário de Araras “Dr. Edmundo Ulson” - UNAR. jaremedio@yahoo.com.br
} 
A morosidade, a excessiva procedimentalização, a falta de transparência e os riscos à segurança jurídica são algumas das dificuldades atribuídas ao processo licitatório regido pelas Leis 8.666/1993, 10.520/2002 e 12.462/2011.

Entre outros aspectos, objetivando modernizar, dar maior transparência, diminuir a burocratização, atribuir maior efetividade, outorgar maior celeridade e ampliar a segurança jurídica nas relações entre a Administração e os particulares, em $1^{\circ}$ de abril de 2021 foi publicada a Lei 14.133/2021, novo marco legislativo das licitações e contratos administrativos no Brasil.

A Lei 14.133/2021 passa a disciplinar as licitações e contratos administrativos, não apenas como um instrumento de unificação do regime jurídico regulamentado anteriormente pelas Leis 8.666/1993, 10.520/2002 e 12.462/2011, mas também como um instrumento normativo que adotou tanto os princípios e valores que conformam as tendências da Administração Pública contemporânea, como os princípios constitucionais e infraconstitucionais que regem a Administração Pública brasileira.

Entre outras novidades, a Lei 14.133/2021, no art. 6 , inciso XLII, criou o diálogo competitivo, objeto específico da presente pesquisa, como modalidade de licitação destinada à contratação de obras, serviços e compras, por meio da qual a Administração Pública "realiza diálogos com licitantes previamente selecionados mediante critérios objetivos, com o intuito de desenvolver uma ou mais alternativas capazes de atender às suas necessidades, devendo os licitantes apresentar proposta final após o encerramento dos diálogos" (BRASIL, 2021).

Como problema da pesquisa, indaga-se se o diálogo competitivo constitui efetivo instrumento procedimental que contribui para o aprimoramento e efetividade das licitações públicas no âmbito do regime licitatório brasileiro.

O estudo tem por objeto analisar o conceito, a estrutura procedimental, as vantagens e as desvantagens relacionadas à modalidade licitatória diálogo competitivo.

No que se refere à estrutura, a pesquisa inicia-se com a análise das modalidades e dos procedimentos auxiliares das licitações no âmbito da Lei 14.133/2021, a segui foca os procedimentos auxiliares das licitações, em seguida aborda o diálogo competitivo como nova modalidade licitatória, e por fim analisa as vantagens e desvantagens inerentes ao diálogo competitivo.

O método utilizado para a realização do estudo é o hipotético-dedutivo, com base na legislação, doutrina e jurisprudência. 
Tem-se, como hipótese, que o diálogo competitivo, enquanto modalidade licitatória, constitui importante instrumento para a transparência, celeridade, efetividade e segurança jurídica do processo licitatório disciplinado pela Lei 14.133/2021.

\section{MODALIDADES DE LICITAÇÕES}

A licitação é conceituada por Hely Lopes Meirelles (2015, p. 302-303) como o procedimento administrativo "mediante o qual a Administração Pública seleciona a proposta mais vantajosa para o contrato de seu interesse, inclusive o da promoção do desenvolvimento econômico sustentável e fortalecimento de cadeias produtivas de bens e serviços domésticos".

Na jurisprudência, conforme entendimento do Supremo Tribunal Federal expressado quando do julgamento da Ação Direta de Inconstitucionalidade 2.716-RO, a licitação é um procedimento que visa à satisfação do interesse público, pautando-se pelo princípio da isonomia, estando voltada para um duplo objetivo, ou seja, o de proporcionar à Administração a possibilidade de realizar o negócio mais vantajoso (o melhor negócio) e o de assegurar aos administrados a oportunidade de concorrerem, em igualdade de condições, à contratação pretendida pela Administração (BRASIL, 2008).

Para o Superior Tribunal de Justiça, de acordo com entendimento expendido quando do julgamento do Recurso Especial 447.814-SP, a licitação identifica-se como um procedimento administrativo com dupla finalidade, uma relativa à escolha da proposta mais vantajosa para a Administração, e a outra relativa ao estabelecimento de igualdade entre os participantes (BRASIL, 2003).

A licitação regida pela Lei 14.133/2021 não só é um processo seletivo, mas também deve cumprir objetivos que vão além da determinação racional-legal do adjudicatário do contrato administrativo, sendo que as inclinações da nova lei mostram a vocação do processo licitatório "para a regulação da economia, tendo em vista o fomento do mercado nacional, a promoção da sustentabilidade, inclusive no emprego, com redução da processualidade e em consonância com a realização de uma política anticorrupção nos contratos públicos” (NÓBREGA, 2019, p. 373).

Nas últimas décadas, firmou-se o entendimento doutrinário no sentido de que a licitação, quanto à finalidade, visa garantir a observância do princípio constitucional da isonomia, a seleção da proposta mais vantajosa para a Administração e a promoção do 
desenvolvimento nacional, ou seja, "é inerente à licitação a obtenção de vantagem para a Administração, com respeito à isonomia ou igualdade entre os participantes" (REMEDIO, 2018, p. 389).

O processo licitatório tem por objetivos, como dispõe o caput do art. 21 da Lei 14.133/2021 (BRASIL, 2021):

I - assegurar a seleção da proposta apta a gerar o resultado de contratação mais
vantajoso para a Administração Pública, inclusive no que se refere ao ciclo de
vida do objeto;
II - assegurar tratamento isonômico entre os licitantes, bem como a justa
competição;
III - evitar contratações com sobrepreço ou com preços manifestamente
inexequíveis e superfaturamento na execução dos contratos;
IV - incentivar a inovação e o desenvolvimento nacional sustentável.

O processo de licitação é integrado pelas seguintes fases, sequencialmente (Lei 14.133/2021, art. 17, caput e incisos I a VII): preparatória; de divulgação do edital de licitação; de apresentação de propostas e lances, quando for o caso; de julgamento; de habilitação; recursal; e de homologação.

As modalidades de licitação previstas na Lei 14.133/2021 são o pregão, a concorrência, o concurso, o leilão e o diálogo competitivo, diferentemente do previsto na legislação anterior revogada pela nova lei, como a Lei 8.666/1993, que previu a concorrência, a tomada de preços, o convite, o concurso e o leilão, e a Lei 10.520/2002, que previu o pregão, embora referidas leis permaneçam ainda em vigor por dois anos contados da data da publicação da nova lei, como previsto no art. art. 193, inciso II, da Lei 14.133/2021.

É vedada a criação de outras modalidades de licitação, ou mesmo a combinação das modalidades previstas no caput do art. 28 , ou seja, pregão, concorrência, concurso, leilão e diálogo competitivo (Lei 14.133/2021, art. 28, § $2^{\circ}$ ).

O pregão, para os fins da Lei 14.133/2021 e conforme previsto no art. $6^{\circ}$, inciso XLI, é "a modalidade de licitação obrigatória para aquisição de bens e serviços comuns, cujo critério de julgamento poderá ser o de menor preço ou o de maior desconto" (BRASIL, 2021).

Segundo Marçal Justen Filho (2015, p. 491), o pregão, em termos sumários, “é uma modalidade de licitação destinada a contratação de bens e serviços comuns, independentemente do valor de que podem participar quaisquer interessados (exceto na forma eletrônica)". 
Não se aplica o pregão em relação às contratações de serviços técnicos especializados de natureza predominantemente intelectual e de obras e serviços de engenharia, exceto quanto aos serviços comuns de engenharia (Lei 14.133/2021, art. 29, parágrafo único).

Serviço comum de engenharia, nos termos da alínea "a" do inciso XXI do caput do art. $6^{\circ}$ da Lei 14.133/2021, é "todo serviço de engenharia que tem por objeto ações, objetivamente padronizáveis em termos de desempenho e qualidade, de manutenção, de adequação e de adaptação de bens móveis e imóveis, com preservação das características originais dos bens" (BRASIL, 2021).

A concorrência, para os fins da Lei 14.133/2021 e como previsto no inciso XXXVIII, "a" a "e" do art. $6^{\circ}$, corresponde à modalidade de licitação para contratação de bens e serviços especiais e de obras e serviços comuns e especiais de engenharia, cujo critério de julgamento poderá ser o menor preço, melhor técnica ou conteúdo artístico, técnica e preço, maior retorno econômico, e maior desconto.

Para Marçal Justen Filho (2015, p. 491), a concorrência “é uma modalidade de licitação de que podem participar quaisquer interessados, promovendo-se o exame da presença dos requisitos de participação no curso do procedimento licitatório", e que pode ser utilizada para qualquer tipo de contrato administrativo, inclusive aqueles que tenham como objeto a alienação de bens e direitos.

Tanto o pregão como a concorrência seguem o mesmo rito procedimental comum a que se refere o art. 17 da Lei 14.133/2021, devendo ser adotado o pregão sempre que o objeto da licitação possuir padrões de desempenho e qualidade que possam ser objetivamente definidos pelo edital, por meio de especificações usuais do mercado (Lei 14.133/2021, art. 29).

O concurso, para os fins da Lei 14.133/2021 e conforme previsto no art. $6^{\circ}$, inciso XXXIX, corresponde à "modalidade de licitação para escolha de trabalho técnico, científico ou artístico, cujo critério de julgamento será o de melhor técnica ou conteúdo artístico, e para concessão de prêmio ou remuneração ao vencedor" (BRASIL, 2021).

Hely Lopes Meirelles (2015, p. 385) define o concurso como "a modalidade de licitação destinada à escolha de trabalho técnico ou artístico, predominantemente de criação intelectual".

O concurso observará as regras e condições previstas no respectivo edital, que indicará: a qualificação exigida dos participantes; as diretrizes e formas de apresentação do 
trabalho; as condições de realização do trabalho e o prêmio ou remuneração a ser concedida ao vencedor (Lei 14.133/2021, art. 30, I a III).

Em relação aos concursos que tenham como objeto a elaboração de projeto, o vencedor deverá ceder à Administração Pública, nos termos do art. 93, os direitos patrimoniais relativos ao projeto e autorizar sua execução conforme juízo de conveniência e oportunidade das autoridades competentes (Lei 14.133/2021, art. 30, parágrafo único).

O leilão, para os fins da Lei 14.133/2021 e como previsto no art. $6^{\circ}$, inciso XL, corresponde à "modalidade de licitação para alienação de bens imóveis ou de bens móveis inservíveis ou legalmente apreendidos a quem oferecer o maior lance” (BRASIL, 2021).

Diogo de Figueiredo Moreira Neto (2014, p. 201) define o leilão como "a modalidade de licitação entre quaisquer interessados para a venda de bens móveis inservíveis para a Administração, ou de produtos legalmente apreendidos ou penhorados, a quem oferecer o maior lance, igual ou superior ao da avaliação".

O leilão será precedido da divulgação do edital em sítio eletrônico oficial, edital esse que deverá conter (Lei 14.133/2021, art. 31, § 2º):

I - a descrição do bem, com suas características, e, no caso de imóvel, sua situação e suas divisas, com remissão à matrícula e aos registros;

II - o valor pelo qual o bem foi avaliado, o preço mínimo pelo qual poderá ser alienado, as condições de pagamento e, se for o caso, a comissão do leiloeiro designado;

III - a indicação do lugar onde estiverem os móveis, os veículos e os semoventes;

IV - o sítio da internet e o período em que ocorrerá o leilão, salvo se excepcionalmente for realizado sob a forma presencial por comprovada inviabilidade técnica ou desvantagem para a Administração, hipótese em que serão indicados o local, o dia e a hora de sua realização;

V - a especificação de eventuais ônus, gravames ou pendências existentes sobre os bens a serem leiloados.

Além de divulgado em sítio eletrônico oficial, o edital do leilão deverá ser afixado em local de ampla circulação de pessoas na sede da Administração Pública, e também poderá ser divulgado por outros meios necessários para ampliar a publicidade e a competitividade da licitação (Lei 14.133/2021, art. 31, § $3^{\circ}$ ).

Nos termos do art. $31, \S 4^{\circ}$, da Lei 14.133/2021, “o leilão não exigirá registro cadastral prévio, não terá fase de habilitação e deverá ser homologado assim que concluída a fase de lances, superada a fase recursal e efetivado o pagamento pelo licitante vencedor, na forma definida no edital" (BRASIL, 2021). 
O diálogo competitivo, objeto específico do presente estudo, conforme art. $6^{\circ}$, inciso XLII da Lei 14.133/2021, é a modalidade de licitação para a contratação de obras, serviços e compras, em que a Administração Pública "realiza diálogos com licitantes previamente selecionados mediante critérios objetivos, com o intuito de desenvolver uma ou mais alternativas capazes de atender às suas necessidades, devendo os licitantes apresentar proposta final após o encerramento dos diálogos" (BRASIL, 2021).

\section{NOÇÕES BÁSICAS SOBFRE OS PROCEDIMENTOS AUXILIARES DAS LICITAÇÕES}

Sem prejuízo das modalidades licitatórias pregão, concorrência, concurso, leilão e diálogo competitivo, a Administração Pública também pode servir-se dos procedimentos auxiliares previstos no art. 78 da nova lei, ou seja, o credenciamento, a pré-qualificação, o procedimento de manifestação de interesse, o sistema de registro de preços e o registro cadastral, conforme previsto no art. 28, $\S 1^{\circ}$, da Lei 14.133/2021.

O credenciamento, nos termos do art. 6 , XLIII, da Lei 14.133/2021, corresponde ao "processo administrativo de chamamento público em que a Administração Pública convoca interessados em prestar serviços ou fornecer bens para que, preenchidos os requisitos necessários, se credenciem no órgão ou na entidade para executar o objeto quando convocados" (BRASIL, 2021).

Poderá ser usado o credenciamento nas seguintes hipóteses de contratação (Lei 14.133/2021, art. 79, incisos I a III):

I - paralela e não excludente: caso em que é viável e vantajosa para a Administração a realização de contratações simultâneas em condições padronizadas;

II - com seleção a critério de terceiros: caso em que a seleção do contratado está a cargo do beneficiário direto da prestação;

III - em mercados fluidos: caso em que a flutuação constante do valor da prestação e das condições de contratação inviabiliza a seleção de agente por meio de processo de licitação.

A pré-qualificação, conforme art. $6^{\circ}$, XLIV, da Lei 14.133/2021, corresponde ao "procedimento seletivo prévio à licitação, convocado por meio de edital, destinado à análise das condições de habilitação, total ou parcial, dos interessados ou do objeto" (BRASIL, 2021). 
O procedimento auxiliar da pré-qualificação é o procedimento técnico-administrativo utilizado para selecionar previamente (Lei 14.133/2021, art. 80, incisos I e II):

I - licitantes que reúnam condições de habilitação para participar de futura licitação ou de licitação vinculada a programas de obras ou de serviços objetivamente definidos;

II - bens que atendam às exigências técnicas ou de qualidade estabelecidas pela Administração.

Em relação ao procedimento de manifestação de interesse, dispõe o art. 81, caput, da Lei 14.133/2021 que (BRASIL, 2021):

A Administração poderá solicitar à iniciativa privada, mediante procedimento aberto de manifestação de interesse a ser iniciado com a publicação de edital de chamamento público, a propositura e a realização de estudos, investigações, levantamentos e projetos de soluções inovadoras que contribuam com questões de relevância pública, na forma de regulamento.

O sistema de registro de preços, conforme art. $6^{\circ}$, XLV, da Lei 14.133/2021, corresponde ao "conjunto de procedimentos para realização, mediante contratação direta ou licitação nas modalidades pregão ou concorrência, de registro formal de preços relativos a prestação de serviços, a obras e a aquisição e locação de bens para contratações futuras" (BRASIL, 2021).

No que se refere ao registro cadastral, dispõe o art. 87 da Lei 14.133/2021, que, para os fins da referida lei, “os órgãos e entidades da Administração Pública deverão utilizar o sistema de registro cadastral unificado disponível no Portal Nacional de Contratações Públicas (PNCP), para efeito de cadastro unificado de licitantes, na forma disposta em regulamento" (caput), sistema esse que será público “e deverá ser amplamente divulgado e estar permanentemente aberto aos interessados, e será obrigatória a realização de chamamento público pela internet, no mínimo anualmente, para atualização dos registros existentes e para ingresso de novos interessados" ( $\left.§ 1^{\circ}\right)$ (BRASIL, 2021).

\section{O DIÁLOGO COMPETITIVO: CARACTERÍSTICAS DA NOVA MODALIDADE LICITATÓRIA}

A modalidade de licitação denominada diálogo competitivo, também conhecida como diálogo concorrencial, é uma das grandes novidades inseridas no ordenamento jurídico brasileiro por meio da Lei 14.133/2021. 
O diálogo competitivo possui inspiração na Diretiva 2014/24 da União Europeia e nas práticas de diálogo e aberturas procedimentais existentes no FAR (Federal Acquisition Regulation) dos Estados Unidos, em especial no item 16.104 do FAR, que contempla uma lista de fatores que podem concorrer para o uso da negociação competitiva (NOHARA, 2018).

Entre as razões existentes para a adoção do diálogo competitivo do modelo da Diretiva n. 2014/24 da União Europeia, onde é conhecido como diálogo concorrencial, podem ser citadas as seguintes (SANTOS, 2019):

a maior flexibilidade de escolha proporcionada às autoridades adjudicantes, por meio de negociação com os licitantes; a intensificação do comércio entre os países fronteiriços (com suas respectivas peculiaridades); a constatação por meio de avaliações/estudos no sentido de que a adoção de procedimento negocial possibilitaria a elevação do número de propostas e maior sucesso na obtenção de soluções aptas ao atendimento da finalidade pretendida.

O diálogo competitivo é definido legalmente no Brasil no inciso XLII do art. $6^{\circ}$ da Lei 14.133/2021 (BRASIL, 2021), como a:

modalidade de licitação para contratação de obras, serviços e compras em que a Administração Pública realiza diálogos com licitantes previamente selecionados mediante critérios objetivos, com o intuito de desenvolver uma ou mais alternativas capazes de atender às suas necessidades, devendo os licitantes apresentar proposta final após o encerramento dos diálogos.

A nova modalidade licitatória, segundo Irene Nohara (2018), possibilitará à Administração saber das soluções inovadoras ou das possibilidades que o mercado dispõe para gerar uma contratação técnica ou com distinta metodologia, que melhor atenda às suas necessidades, pois a Administração nem sempre possui conhecimentos suficientemente atualizados para tanto, dada a dinamicidade própria do mercado, ou, ainda, aqueles de domínio restrito para formulação de contratações complexas ou inovadoras customizadas.

O legislador, com o diálogo competitivo, "pretende que empresas privadas e poder público desenvolvam um diálogo prévio, com o objetivo de desenvolver alternativas que melhor se enquadrem às necessidades da Administração Pública, por meio de obtenção de propostas/soluções efetivas" (SANTOS, 2019).

O diálogo competitivo visa a transpor as dificuldades enfrentadas pelo Poder Público nas contratações de objetos complexos e inovadores, sendo que a Administração Pública, por meio da modalidade, define suas necessidades e os critérios da pré-seleção dos licitantes e, a partir disso, inicia diálogos com os licitantes selecionados, de forma a obter informações e 
alternativas de soluções, estendendo-se o diálogo até que seja possível definir a solução mais adequada e, a partir de então, todos os licitantes selecionados podem apresentar suas propostas (ZAGO; RODRIGUES, 2019).

Em linhas gerais, o diálogo competitivo destina-se às contratações complexas da Administração Pública, tendo o diálogo como instrumento com a iniciativa privada. Inicialmente, o órgão ou entidade que deseja licitar define suas necessidades e os critérios a serem utilizados para previamente selecionar os participantes. Em seguida, os selecionados participam de sessões com o objetivo de promover trocas de informações e apresentar soluções para os problemas referentes ao objeto complexo da licitação. Terminado o diálogo com a definição da solução mais adequada, os licitantes apresentam suas propostas (DIAS, 2020, p. 74).

Em certo sentido, o diálogo competitivo assemelha-se ao procedimento auxiliar de manifestação de interesse previsto na Lei 14.133/2021 (art. 78, III, e 81, caput), uma vez que ambos institucionalizam, de maneira próxima, a participação da iniciativa privada na fase de estudos, investigações, levantamentos e projetos de soluções inovadoras nas contratações públicas.

Todavia, enquanto o processo de manifestação de interesse se realiza antes da licitação, o diálogo competitivo abrirá a interlocução, ou seja, o debate com os licitantes que participam da licitação. Assim, o diálogo competitivo caracteriza-se como uma modalidade de licitação mais flexível, isto é, que abre oportunidade para a Administração Pública “estabelecer, no curso do certame, a solução que melhor atenda suas necessidades (após o diálogo estimulado dentro do procedimento licitatório), daí, em fase subsequente (competitiva), os licitantes terão oportunidade de apresentar propostas com base nessa solução" (NOHARA, 2018).

O diálogo competitivo, entre outros aspectos, legitima e concede transparência e segurança jurídica para um fato inerente à relação entre a Administração Pública e o particular, ou seja, o contato prévio entre as partes, para a apresentação de soluções fornecidas pela iniciativa privada, e que podem interessar à Administração Pública (LAHOZ, 2021, p. 74).

Quanto às hipóteses de contratação, o diálogo competitivo é restrito a contratações em que a Administração Pública (Lei 14.133/2021, I e II): 
I - objetive contratar objeto que envolva determinadas condições, ou seja: em que haja inovação tecnológica ou técnica, em que haja impossibilidade de o órgão ou entidade ter sua necessidade satisfeita sem a adaptação de soluções disponíveis no mercado, e em que haja impossibilidade de as especificações técnicas serem definidas com precisão suficiente pela Administração (inciso I).

II - constate a necessidade de definir e identificar os meios e as alternativas que possibilitem satisfazer suas necessidades ou demandas, especialmente no que se refere à solução técnica mais adequada, aos requisitos técnicos aptos a concretizar a solução já definida, e à estrutura jurídica ou financeira do contrato (inciso II, "a" a "c").

As negociações, no âmbito do diálogo competitivo, "podem envolver não apenas a definição do objeto a ser contratado, mas também a estrutura e as condições contratuais, como prazos, fases de desenvolvimento e fornecimento do objeto e formas de remuneração do privado" (ZAGO; RODRIGUES, 2019).

Apesar da restrição prevista no art. 32 da Lei 14.133/2021, a lei em questão admite a aplicação do diálogo competitivo em relação às concessões de serviços públicos e às parcerias público-privadas.

No que se refere às concessões de serviços públicos e às parcerias público-privadas, a Administração nem sempre possui "a exata noção de como instrumentalizar uma contratação desse porte, voltado para a infraestrutura, com elevado valor, investimentos pesados, contrapartidas do Poder Público (no caso das parcerias público-privadas) e as técnicas possíveis de serem empregadas" (LAHOZ, 2021, p. 75).

Assim, o diálogo competitivo passou a integrar os conceitos legais de concessão de serviço público e de concessão de serviço público precedida da execução de obra pública, previstos na Lei 8.987/1995, art. $2^{\circ}$, incisos II e III, respectivamente, na redação dada pelo art. 179 da Lei 14.133/2021.

A concessão de serviço público, conforme art. $2^{\circ}$, II, da Lei 8.987/1995, corresponde à “delegação de sua prestação, feita pelo poder concedente, mediante licitação, na modalidade concorrência ou diálogo competitivo, a pessoa jurídica ou consórcio de empresas que demonstre capacidade para seu desempenho, por sua conta e risco e por prazo determinado" (BRASIL, 1995).

A concessão de serviço público precedida da execução de obra pública, nos termos do art. $2^{\circ}$, III, da Lei 8.987/1995 (BRASIL, 1995), corresponde à: 
construção, total ou parcial, conservação, reforma, ampliação ou melhoramento de quaisquer obras de interesse público, delegados pelo poder concedente, mediante licitação, na modalidade concorrência ou diálogo competitivo, a pessoa jurídica ou consórcio de empresas que demonstre capacidade para a sua realização, por sua conta e risco, de forma que o investimento da concessionária seja remunerado e amortizado mediante a exploração do serviço ou da obra por prazo determinado.

Do mesmo modo, o diálogo competitivo também está relacionado à licitação e contratação de parceria público-privada no âmbito da Administração Pública.

Dessa forma, nos termos do caput do art. 10 da Lei 11.079/2004 (na redação dada pelo art. 180 da Lei 14.133/21), “a contratação de parceria público-privada será precedida de licitação na modalidade concorrência ou diálogo competitivo, estando a abertura do processo licitatório condicionada a" diversos requisitos, conforme incisos I a VI do referido art. 10 da Lei 11.079/2004 (BRASIL, 2004).

Em relação ao rito procedimental da modalidade de licitação diálogo competitivo, devem ser observadas as seguintes disposições (Lei 14.133/2021, art. 32, § $1^{\circ}$ ):

a) a Administração apresentará, por ocasião da divulgação do edital em sítio eletrônico oficial, suas necessidades e as exigências antes definidas e estabelecerá prazo mínimo de 25 dias úteis para manifestação de interesse na participação da licitação (inciso I);

b) devem estar previstos no edital os critérios empregados para pré-seleção dos licitantes, devendo ser admitidos todos os interessados que preencham os requisitos objetivos nele estabelecidos (inciso II);

c) é vedada a divulgação de informações de modo discriminatório que possa implicar vantagem para algum licitante (inciso III);

d) a Administração não poderá revelar a outros licitantes as soluções propostas ou as informações sigilosas comunicadas por qualquer licitante, sem que haja o seu consentimento (inciso IV);

e) a fase de diálogo poderá ser mantida, até que a Administração, em decisão fundamentada, identifique a solução ou as soluções que atendam às suas necessidades (inciso V);

f) as reuniões com os licitantes pré-selecionados serão registradas em ata e gravadas por meio utilização de recursos tecnológicos de áudio e vídeo (inciso VI);

g) o edital poderá prever a realização de fases sucessivas, hipótese em que cada fase poderá restringir as soluções ou as propostas a serem discutidas (inciso VII); 
h) a Administração deverá, ao declarar que o diálogo foi concluído, juntar aos autos do processo os registros e as gravações da fase de diálogo, dar início à fase competitiva com a divulgação de edital contendo a especificação da solução que atenda às suas necessidades e os critérios objetivos que serão utilizados para seleção da proposta mais vantajosa e abrir prazo, não inferior a sessenta dias úteis, para que todos os licitantes pré-selecionados na forma do inciso II do $\S 1^{\circ}$ do art. 32 apresentarem suas propostas, que deverão conter os elementos necessários para a realização do projeto" (inciso VIII);

i) a Administração poderá solicitar esclarecimentos ou ajustes às propostas apresentadas, desde que tais medidas não impliquem discriminação nem distorçam a concorrência entre as propostas (inciso IX);

j) a Administração definirá a proposta vencedora de acordo com critérios divulgados no início da fase competitiva, assegurada como resultado a contratação mais vantajosa (inciso $\mathrm{X}$ );

k) o diálogo competitivo será conduzido por comissão de contratação composta por pelo menos 3 servidores efetivos ou empregados públicos pertencentes aos quadros permanentes da Administração, sendo admitida a contratação de profissionais para assessoramento técnico da comissão (inciso XI).

A comissão de licitação referida no inciso XI do parágrafo $1^{\circ}$ do art. 32 da Lei 14.133/2021, corresponde ao "conjunto de agentes públicos indicados pela Administração, em caráter permanente ou especial, com a função de receber, examinar e julgar documentos relativos às licitações e aos procedimentos auxiliares" (Lei 14.133/2021, art. 6 ${ }^{\circ}$, L) (BRASIL, 2021).

Os profissionais contratados para os fins do inciso XI do $\S 1^{\circ}$ do art. 32, ou seja, servidores efetivos ou empregados públicos pertencentes aos quadros permanentes da Administração, assinarão termo de confidencialidade e abster-se-ão de atividades que possam configurar conflito de interesses (Lei 14.133/2021, art. 32, § $2^{\circ}$ ).

Rodrigo Augusto Lazzari Lahoz (2021, p. 75-76), ao comentar o Projeto de Lei que deu origem à Lei 14.133/2021, afirma que o rito procedimental do diálogo competitivo estabelecido pelo $\S 1^{\circ}$ do art. 32 do Projeto (texto esse mantido em linhas gerais no $\S 1^{\circ}$ do art. 32 da Lei 14.133/2021), pode ser dividido em duas etapas, a primeira consistente no diálogo entre a Administração e os particulares, e a segunda, correspondente à fase competitiva: 
a) inicialmente, deve-se instaurar uma comissão que conduzirá a contratação, integrada por pelo menos três servidores efetivos ou empregados públicos, podendo ser contratados profissionais técnicos especializados para assessorar tecnicamente a comissão (inciso XI), profissionais esses que assinarão termo de confidencialidade e não poderão participar de atividades que impliquem em conflito de interesses $\left(\S 2^{\circ}\right)$;

b) a fase do diálogo tem início com a publicação do edital, apresentando as necessidades e exigências da Administração, bem como estabelecendo um prazo mínimo de 25 dias úteis para manifestação dos interessados em participar da licitação; o edital deverá apresentar os critérios para pré-seleção dos interessados (incisos I e II), sendo vedada no curso do diálogo a divulgação de informações que importem em vantagem para um ou mais licitantes e das soluções propostas pelos licitantes (incisos III e IV);

c) ao final da fase de diálogo, a Administração indicará as soluções que atendam às suas necessidades (incisos V, VI e VII), sendo que a solução desejada poderá partir de um ou mais licitantes, inclusive através da combinação das propostas apresentadas;

d) encerrada a fase do diálogo, passa à fase de competição, prevista nos incisos VIII, IX e X, devendo a Administração deflagrar um novo edital para contratar a solução desejada apresentada na fase do diálogo, edital esse que conterá as especificações da solução a ser encontrada e os critérios objetivos para a seleção da proposta mais vantajosa.

Tamanha é a importância do diálogo competitivo, que seu desrespeito implica na prática de crime.

Nesse sentido, o art. 178 da Lei 14.133/2021 acrescentou no Título XI da Parte Especial do Código Penal o Capítulo II-B, intitulado Dos Crimes em Licitações e Contratos Administrativos, integrado pelos artigos 337-E a 337-P.

Por sua vez, o art. 337-O do Código Penal, inserido pelo art. 178 da Lei 14.133/2021, denominado omissão grave de dado ou de informação por projetista, possui aplicação em relação à modalidade licitatória diálogo competitivo.

E, nos termos do art. 337-O, caput, do Código Penal - Decreto-Lei 2.848/1940, constitui crime de omissão grave de dado ou de informação por projetista, punível com reclusão de seis meses a três anos e multa (BRASIL, 1940):

Omitir, modificar ou entregar à Administração Pública levantamento cadastral ou condição de contorno em relevante dissonância com a realidade, em frustração ao caráter competitivo da licitação ou em detrimento da seleção da proposta mais vantajosa para a Administração Pública, em contratação para a 
elaboração de projeto básico, projeto executivo ou anteprojeto, em diálogo competitivo ou em procedimento de manifestação de interesse.

As penas de reclusão de seis meses a três anos e multa previstas em relação ao caput do art. 337-O do Código Penal, serão aplicadas em dobro, conforme $\S 2^{\circ}$ do art. 337-O do estatuto substantivo penal, caso o crime venha a ser praticado com o fim de obter benefício, direto ou indireto, próprio ou de outrem.

\section{CRÍTICAS AO DIÁlOGO COMPETITIVO}

A nova modalidade licitatória denominada diálogo competitivo, prevista na Lei 14.133/2021, tem despertado muitas dúvidas quanto a seus contornos e aplicação no sistema brasileiro de licitações e contratos administrativos.

De um lado, são bastante expressivas as vantagens atribuíveis pela doutrina ao diálogo competitivo.

Assim, o diálogo competitivo mostra-se em linhas gerais como um procedimento licitatório negocial, flexível e transparente, que confere segurança jurídica à Administração e aos licitantes, diante da necessidade de contratar objetos complexos.

Marçal Justen Filho (2015), depois de afirmar que todas as leis de licitação vigentes são ruins porque não contemplam mecanismos de participação, discussão e disputa efetiva entre os licitantes, apresenta a ampliação da competição como única forma para resolver o problema. Para o autor, isso envolve não apenas alterar radicalmente a disciplina da habilitação regida pela Lei 8.666/1993, mas também a necessidade de se consagrar o chamado diálogo competitivo, permitindo que os competidores exerçam o controle entre si.

O diálogo competitivo tende a melhor instruir a Administração na compreensão das alternativas e dos riscos envolvidos na contratação pretendida, possibilitando ainda maior alinhamento entre os interesses e as expectativas das partes contratantes, bem como "favorecendo a construção de soluções com maior aderência aos anseios da Administração Pública. Como consequência, esses fatores tendem a agregar maior consistência, estabilidade e segurança jurídica nas contratações públicas” (ZAGO; RODRIGUES, 2019).

A nova modalidade licitatória possibilitará a abertura do mercado para a contratação de obras, serviços e compras, com a participação de um número maior de interessados em comparação aos demais modelos licitatórios previstos na Lei 14.133/2021, como o pregão, a concorrência, o concurso e o leilão. 
O novo modelo licitatório afasta a presunção anteriormente existente, no sentido de que a Administração Pública possui total e plena capacidade de prever, isoladamente, sem o auxílio de terceiros, todas as possíveis soluções que atendam às suas necessidades, em especial diante dos mais variados e complexos ramos de atividade do mercado, como o relativo às inovações tecnológicas.

O diálogo competitivo, conforme referência de Santos (2021), “irá se prevenir a elaboração de editais de maneira unilateral e isolada pela Administração, que por vezes culminam na celebração de contratos deficientes ou que não se enquadram ao que o mercado oferece de melhor (serviços/produtos)".

O novo modelo possibilitará o acesso a novos produtos e serviços, inclusive relacionados aos mais variados ramos de atividade, independentemente de sua complexidade, possibilitando o adequado e eficiente atendimento ao interesse público e aos interesses da coletividade.

De outro lado, também são várias as desvantagens atribuíveis ao diálogo competitivo pela doutrina.

Assim, conforme referência de Santos (2019), pode-se apontar em relação à nova modalidade licitatória a existência de muitos termos e expressões vagas utilizadas pela Lei 14.133/2021, como ocorre com o art. 29, inciso I, que, ao tratar das condições que devem envolver o objeto a ser contratado, utiliza-se das expressões "inovação tecnológica ou técnica" e "possibilidade de execução com diferentes metodologias", sem que haja qualquer definição ou detalhamento mais claro sobre o conteúdo das expressões.

Também é questionável o inciso XI do art. 32 da Lei 14.133/2021, ao dispor que o diálogo competitivo será conduzido por comissão de contratação composta de pelo menos três servidores efetivos ou empregados públicos pertencentes aos quadros permanentes da Administração Pública, sendo admitida a contratação de profissionais para assessoramento técnico da comissão, isso porque falta ao texto normativo a efetiva previsão de mecanismos institucionais com contornos mais definidos, seguros e transparentes no que se refere à condução do processo licitatório da nova modalidade licitatória.

Para Ricardo Marcondes Martins (2016), se, de um lado, o diálogo competitivo pareça ser fantástico, uma vez que os agentes da Administração dialogam com os licitantes para a obtenção do melhor para o interesse público, de outro lado, também é possível pela nova 
modalidade licitatória contornar a disputa para favorecer alguém específico, burlando assim a competição.

O custo da operacionalização do diálogo competitivo também é citado como uma das desvantagens para seu uso, diante das sucessivas fases inerentes à nova modalidade licitatória, que demandam tempo e pessoas à disposição para a realização da tarefa, tanto para o setor público como para o setor privado (RAINHO, 2019).

Também podem dificultar a operacionalização do diálogo repetitivo: a incerteza quanto aos objetos que devem possibilitar sua utilização (RAINHO, 2019): a verificação da capacidade técnica, econômica e profissional dos licitantes; e qual a margem aceitável para mudanças e negociações antes e depois da avaliação das propostas.

Pode-se ainda apontar, em relação à nova modalidade licitatória, as dificuldades de comparar apenas numerica ou objetivamente, propostas de soluções diversas para a necessidade pública, e também de estimular a participação dos licitantes, tendo em vista que destes será exigido o trabalho sem quaisquer garantias ou remuneração (DIAS, 2010, p. 7576).

Sob nossa ótica, a comparação entre os diversos elementos consubstanciados em vantagens e desvantagens, como antes discriminados, atribuíveis ao diálogo competitivo, possibilita concluir que a nova modalidade licitatória possui importantes características positivas e vantajosas para o interesse público e os interesses da coletividade, que poderão contribuir para a celeridade, efetividade e transparência das licitações públicas, inclusive para a ampliação da segurança jurídica no que se refere às contratações públicas celebradas entre a Administração Pública e os particulares.

\section{CONCLUSÃO}

O regime jurídico brasileiro das licitações públicas e contratos administrativos esteve pautado nas últimas décadas pelas Leis 8.666/1993, 10.520/2002 e 12.462/2011, sendo muitas as críticas atribuídas a referido modelo jurídico, destacando-se a morosidade, excesso de burocracia, falta de transparência e ausência de efetividade do processo licitatório, com riscos à própria segurança jurídica nas relações entre a Administração Pública e o particular.

A Lei 14.133/2021, novo marco normativo das licitações e contratos administrativos, não só promoveu a unificação do regime jurídico licitatório consolidando em texto único parte 
expressiva dos institutos anteriormente regulados pelas Leis 8.666/1993, 10.520/2002 e 12.462/2011, mas também criou novos e importantes institutos sobre as licitações e contratos administrativos, inclusive com a adoção dos princípios e valores que conformam as tendências da Administração Pública contemporânea, e também dos princípios constitucionais e infraconstitucionais que regem a Administração Pública brasileira.

O processo licitatório regido pela nova lei tem por objetivos (Lei 14.133/2021): assegurar a seleção da proposta apta a gerar o resultado de contratação mais vantajoso para a Administração, inclusive no tocante ao ciclo de vida do objeto do contrato; assegurar tratamento isonômico entre os licitantes, assim como a justa competição; evitar contratações com sobrepreço ou com preços inexequíveis e superfaturamento na execução dos contratos; e incentivar a inovação e o desenvolvimento nacional sustentável.

Entre as novidades criadas pela Lei 14.133/2021, destaca-se o diálogo competitivo, previsto no art. $6^{\circ}$, inciso XLII, como modalidade de licitação destinada à contratação de obras, serviços e compras, por meio da qual a Administração Pública realiza diálogos com licitantes previamente selecionados através de critérios objetivos, com o objetivo de desenvolver uma ou mais alternativas capazes de atender às suas necessidades, devendo os licitantes apresentar proposta final uma vez encerrados os diálogos.

O diálogo competitivo, ainda que sem unanimidade na doutrina, foi inspirado na Diretiva n. 2014/24 da União Europeia, onde é conhecido como diálogo concorrencial, em que tem como características, entre outras, maior flexibilidade procedimental proporcionada às autoridades, por meio da negociação com os licitantes.

A nova modalidade licitatória visa a superar as dificuldades enfrentadas pela Administração Pública nas contrações de objetos complexos e inovadores, por meio de diálogos com os licitantes previamente selecionados no processo, obtendo com isso informações e alternativas de soluções para suas necessidades, com a apresentação, ao final, de propostas por todos os licitantes selecionados.

Entre as possíveis desvantagens procedimentais e práticas ao diálogo competitivo, podem ser citadas: a existência alguns termos vagos e imprecisos no texto legal, como ocorre no art. 29, I, da Lei 14.133/2021, dificultam a compreensão e a aplicação do instituto; o art. 32, XI, da Lei 14.133/2021, ao tratar da condução do processo licitatório por comissão de contratação, deixa de apresentar efetiva previsão de mecanismos institucionais com contornos mais definidos, seguros e transparentes; a nova modalidade, ao se valer da negociação e 
diálogo com os licitantes, poderá possibilitar o contorno da disputa, para favorecer alguém específico, burlando assim a licitação; o custo da operacionalização do novo modelo poderá ser um entrave para sua realização, diante das sucessivas fases inerentes à nova modalidade licitatória; as dificuldades de comparar apenas mumericamente propostas de soluções diversas para a necessidade pública; e a dificuldade de se estimular a participação dos interessados, uma vez que deles será exigido o trabalho, sem que haja garantia ou remuneração.

Por outro lado, entre as vantagens procedimentais e práticas atribuíveis o diálogo competitivo, com as quais concordamos, podem ser citadas: o acesso à Administração de soluções inovadoras às suas atividades e funções; a possibilidade de o mercado possibilitar a geração de contratações técnicas ou com distintas tecnologias que melhor atendam às suas necessidades; a maior flexibilidade e transparência do procedimento licitatório; a ampliação da segurança jurídica em relação à Administração e aos licitantes; o aumento da competição entre os diversos participantes; e o acesso a novos produtos e serviços, independentemente de sua complexidade, atendendo de forma mais eficiente ao interesse público e à coletividade.

Tem-se, em conclusão, que que o diálogo competitivo criado e disciplinado pela Lei 14.133/2021 - Lei de Licitações e Contratos Administrativos, enquanto modalidade licitatória, constitui importante instrumento para a transparência, efetividade, celeridade e segurança jurídica do processo licitatório brasileiro.

\section{REFERÊNCIAS}

BRASIL. Decreto-Lei 2.848, de 7 de dezembro de 1940 - Código Penal. Disponível em: http://www.planalto.gov.br/ccivil_03/decreto-lei/del2848compilado.htm. Acesso em: 10 abr. 2021.

BRASIL. Lei 8.987, de 13 de fevereiro de 1995. Disponível em: http://www.planalto.gov.br/ccivil_03/LEIS/L8987cons.htm. Acesso em: 10 abr. 2021.

BRASIL. Lei 11.079, de 30 de dezembro de 2004. Disponível em: http://www.planalto.gov.br/ccivil_03/_Ato2004-2006/2004/Lei/L11079compilado.htm.

Acesso em: 10 abr. 2021.

BRASIL. Lei 14.133, de $1^{\circ}$ de abril de 2021. Disponível em: http://www.planalto.gov.br/ccivil_03/_ato2019-2022/2021/lei/L14133.htm. Acesso em: 10 abr. 2021. 
BRASIL. Superior Tribunal de Justiça. Recurso Especial 447.814-SP. Relator Ministro José Delgado. Brasília: DJ, 10 mar. 2003, p. 112.

BRASIL. Supremo Tribunal Federal. Ação Direta de Inconstitucionalidade 2.716-RO. Relator Ministro Eros Grau. Brasília: DJe, 7 mar. 2008. Disponível em: https://jurisprudencia.stf.jus.br/pages/search?base=acordaos\&sinonimo=true $\&$ plural=true $\&$ pa ge=1\&pageSize=10\&queryString=adi\%202716\&sort=_score\&sortBy=desc. Acesso em: 11 abr. 2021.

DIAS, Lidiane Dutra. Projeto da nova lei de licitações: uma análise dos principais avanços e críticas. Revista Vertentes do Direito, v. 7. n. 2, p. 50-80, 2020.

JUSTEN FILHO, Marçal. Coluna da Gazeta do Povo: mas temos muito mais a falar sobre licitação. 2015. Disponível em: http://justenfilho.com.br/tags/lei-8666/. Acesso em: 11 abr. 2021.

JUSTEN FILHO, Marçal. Curso de direito administrativo. 11. ed. São Paulo: Revista dos Tribunais, 2015.

LAHOZ, Rodrigo Augusto Lazzari. Modalidades de licitação e procedimentos auxiliares Capítulo 6. In: NIEBUHR, Joel de Menezes (Coord.). Nova lei de licitações e contratos administrativos. Zênite Editora, 2021, p. 68-79. E-book. Disponível em: https://www.zenite.blog.br/wp-content/uploads/2020/12/Nova-Lei-de-

Licitac\%CC\%A7o\%CC\%83es-e-Contratos-Administrativos.pdf. Acesso em: 10 fev. 2021.

MARTINS, Ricardo Marcondes. Reforma da Lei de Licitações: como podemos piorar? Direito do Estado, ano 2016, n. 280. Disponível em: http://www.direitodoestado.com.br/colunistas/ricardo-marcondes-martins/reforma-da-lei-delicitacoes-como-podemos-piorar. Acesso em: 11 abr. 2021.

MEIRELLES, Hely Lopes. Direito administrativo brasileiro. 41. ed. São Paulo: Malheiros, 2015.

MOREIRA NETO, Diogo de Figueiredo. Curso de direito administrativo: parte introdutória, parte geral e parte especial. 16. ed. Rio de Janeiro: Forense, 2014.

NÓBREGA, Theresa. A nova lei de licitações no Brasil: a licitação diante das transições legislativas. Revista da AGU, Brasília, v. 18, n. 2, p. 349-376, abr./jun. 2019.

NOHARA, Irene. Diálogo competitivo. Direito administrativo. 2018. Disponível em: https://direitoadm.com.br/dialogo-competitivo/\#_ftn1. Acesso em: 10 abr. 2021. 
RAINHO, Renata Vaz Marques Costa. A aplicação da modalidade licitatória diálogo competitivo ao direito administrativo brasileiro. 2019. Disponível em: https://www.researchgate.net/publication/337146205_A_Aplicacao_da_Modalidade_Licitator ia_Dialogo_Competitivo_ao_Direito_Administrativo_Brasileiro. Acesso em: 11 abr. 2021. REMEDIO, José Antonio. Direito administrativo. 3. ed. São Paulo: Verbatim, 2018.

SANTOS, Marcello Leite dos. Licitações: as legislações pertinentes e Projeto de Lei n. 6814/2017. 2019. Disponível em: http://www.tce.ms.gov.br/portalservices/files/arquivo/nome/13958/6fac64fb1baf5b6e872c968984b737be.pdf. Acesso em: 10 abr. 2021.

ZAGO, Marina; RODRIGUES, Fernanda. O que o diálogo competitivo agrega às contratações públicas? Consultor Jurídico. 2019. Disponível em: https://www.conjur.com.br/2019-nov-11/opiniao-dialogo-competitivo-agrega-contratacoespublicas. Acesso em: 11 abr. 2021. 